\title{
OS FITOTERÁPICOS E SEU POTENCIAL NA CICATRIZAÇÃO EM CIRURGIA
}

\author{
Osvaldo Malafaia ${ }^{1}$, Antonio Carlos Ligocki Campos², Orlando Torres ${ }^{3}$, Saul Goldenberg ${ }^{4}$ \\ 1. Coordenador Acadêmico do MINTER/CAPES UFPR-UFMA (2002-2004) \\ 2. Coordenador do Programa de Pós-Graduação em Clínica Cirúrgica do Setor de Ciências da Saúde da UFPR (2000-2004) \\ 3. Coordenador Operacional do MINTER/CAPES UFPR-UFMA (2002-2004) \\ 4. Editor-in-Chief da Acta Cirúrgica Brasileira
}

..." as árvores produzirão novos frutos de mês a mês, porque sua água provém do santuário; seus frutos servirão de alimento e suas folhas de remédio "...

Apocalipse de São João (Apocalipse 22:2)

O Brasil é caracterizado internacionalmente como possuidor da maior reserva florestal diversificada do planeta. O potencial dessa flora para uso na medicina tem sido destacado no meio científico interessado em descobrir novas substâncias que possam estimular a reparação cirúrgica. Contudo, ainda é incipiente o que existe de trabalhos com metodologia cientificamente estruturada. A maior parte das publicações são de ensaios empíricos baseados no dito popular.

A fitoterapia tem dificuldade intrínseca de fazer reconhecer a(s) substância(s) que apresenta o fator terapêutico. O fracionamento da forma de extrato à fração um (ou substância ativa) leva muito tempo para ser feito, porque não é incomum que ele possua mais de mil elementos químicos dos quais somente um ou alguns poucos têm atividade terapêutica. Assim é que o valor da fração 10, ou seja, um grupo de 10 elementos químicos dentre os quais existe o(s) procurado (s), tem valor econômico muito alto e é comprado pela indústria farmacêutica que em seus laboratórios de pesquisa prosseguem o fracionamento até o elemento ativo. Uma vez sendo atingida esta etapa, pode a substância ser pesquisada com vistas a sua utilização futura para uso humano.

Embora apresentando-se como difícil e longo caminho, esta foi a maneira com que muitos dos medicamentos hoje largamente utilizados tiveram que se submeter para atingir o estágio de comercialização e uso corrente na prática médica.

O Estado do Maranhão no Brasil possui densa flora grandemente diversificada. Na medicina popular - que é lá de uso corrente -, a fitoterapia tem na tradição a indicação em doenças ou condições patológicas. De modo geral são muito diversas e, por vezes, folclóricas. É claro que a ciência tem sua função aí bem estabelecida, ou seja, buscar a verdade utilizando o método científico bem estruturado para separar dela o mito.

É o que a Universidade Federal do Paraná - UFPR em Curitiba - PR e a Universidade Federal do Maranhão - UFMA em São Luiz - MA, fizeram com um projeto de Mestrado Interinstitucional - MINTER aprovado pela CAPES, realizado e finalizado recentemente. A UFPR tem em seu Programa de Pós-Graduação stricto sensu em Clínica Cirúrgica - níveis de mestrado e doutorado -, linha de pesquisa consolidada em Cicatrização de Feridas Cirúrgicas. A UFMA tem tradição de pesquisa em plantas medicinais, possui herbário próprio delas e fabrica artesanalmente ampla gama de produtos, em sua maioria na forma de extratos, que são distribuídos à população carente quando medicamente indicados.

Ao longo de dois anos, 21 experimentos foram realizados com quatro plantas que já apresentavam sinalização científica anterior de possuírem ações terapêuticas na cicatrização de ferimentos diversos. Foram elas Passiflora edulis (maracujá), Schinus terebinthifolius raddi (aroeira), Jatropha gossypiifolia L (pião roxo) e a Orbignya phalerata (babaçu). Como tema de teses de mestrado, produziram-se experimentos cirúrgicos metodologicamente adequados envolvendo vários segmentos anatômicos do animal de experimentação na intenção de confirmar ou não as ações terapêuticas a elas atribuídas.

Nos dois números suplementares da ACTA CIRÚRGICA BRASILEIRA (Volume 21, Suppl 2 e 3) apresentam-se os trabalhos que resultaram destas pesquisas integradas. É claro, este é um primeiro passo que necessita continuidade buscando, mais do que a sinalização aqui mostrada, comprovar o real efeito no mecanismo de cicatrização, a dose que deve ser indicada, a concentração do extrato, a via de inoculação e mais ainda a realização do fracionamento para aproximar-se do(s) elemento(s) que é responsável pala ação terapêutica.

Muitos anos e muito trabalho se vislumbram pela frente. Mas, a ciência médica é assim, caminha em passos lentos, contudo com segurança muito grande e tem na cirurgia experimental aliado fundamental para desenvolver produtos e meios que o homem precisa para minimizar as dores físicas pelas quais terá que passar em sua vida. No dizer de Renan (1823-1892) em seu livro "O futuro da humanidade" a ciência é a mãe do conhecimento e da melhoria da vida humana, quando fala:..."Na ciência permanecerá sempre a satisfação do desejo mais alto da nossa natureza, a curiosidade; ela fornecerá sempre ao homem o único meio que ele possui para melhorar a própria sorte”. 